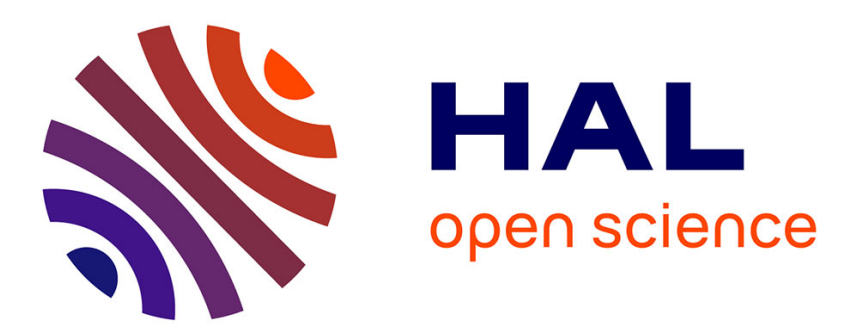

\title{
Detection and characterisation of heterogeneities in the WISDOM/ExoMars 2022 radargrams.
}

François-Wandrille de Lamberterie, Nicolas Oudart, Valérie Ciarletti, Alice Le Gall, Yann Herve

\section{- To cite this version:}

François-Wandrille de Lamberterie, Nicolas Oudart, Valérie Ciarletti, Alice Le Gall, Yann Herve. Detection and characterisation of heterogeneities in the WISDOM/ExoMars 2022 radargrams.. European Planetary Science Congress. EPSC 2021, Sep 2021, Virtual Meeting, France. 10.5194/epsc2021-478 . insu-03323732

\section{HAL Id: insu-03323732 \\ https://hal-insu.archives-ouvertes.fr/insu-03323732}

Submitted on 22 Aug 2021

HAL is a multi-disciplinary open access archive for the deposit and dissemination of scientific research documents, whether they are published or not. The documents may come from teaching and research institutions in France or abroad, or from public or private research centers.
L'archive ouverte pluridisciplinaire HAL, est destinée au dépôt et à la diffusion de documents scientifiques de niveau recherche, publiés ou non, émanant des établissements d'enseignement et de recherche français ou étrangers, des laboratoires publics ou privés. 
EPSC Abstracts

Vol. 15, EPSC2021-478, 2021, updated on 30 Jul 2021

https://doi.org/10.5194/epsc2021-478

European Planetary Science Congress 2021

(C) Author(s) 2021. This work is distributed under

the Creative Commons Attribution 4.0 License.

\section{Detection and characterisation of heterogeneities in the WISDOM/ExoMars 2022 radargrams.}

François-Wandrille De Lamberterie ${ }^{1}$, Nicolas Oudart ${ }^{1}$, Valérie Ciarletti ${ }^{1}$, Alice Le Gall ${ }^{1,2}$, and Yann $^{2}$ Hervé $^{1}$

${ }^{1}$ Université de Versailles Saint-Quentin, LATMOS, PLANETO, Guyancourt, France (nicolas.oudart@latmos.ipsI.fr)

${ }^{2}$ Institut Universitaire de France, Paris, France

\section{Introduction}

The principal objective of Rosalind Franklin, the ExoMars Rover, is to look for evidence of past or present life on Mars. Such evidence would most likely remain in the subsurface, where organic molecules are protected from all kind of threats they could meet at the surface. For this reason, the ExoMars Rover mission has been optimized to investigate the subsurface to identify, understand, and sample those locations where conditions for the preservation of former past life are most likely to be found. The Water Ice Subsurface Deposit Observation on Mars (WISDOM) groundpenetrating radar has been designed to provide information about the nature of the shallow subsurface over depth ranging from 3 to $10 \mathrm{~m}$ (with a vertical resolution of up to $\mathbf{3} \mathbf{~ c m})$, depending on the ground's dielectric properties.

WISDOM radargrams help to understand the geologic stratigraphy and structures of the subsurface, including potential ice formations. They provide important clues about the identification of optimal drilling sites for investigation and sampling by the Rover's 2-m drill. WISDOM will also ensure the safety and success of drilling operations by detecting potential hazards that might damage the drill and jeopardize the retrieval of subsurface samples. The interpretation of these radargrams is a crucial point in the research process, and many tools are developed to analyse and understand all the data provided.

When the soil does not have any clear geological stratification or big reflectors such as buried stones, it can still provide information about its structure. The heterogeneity of the soil could reveal interesting mixed composition of two different materials, or with little structures too small to be detected by WISDOM. The objective of this study is to characterise the heterogeneities of the subsurface using different criteria. 


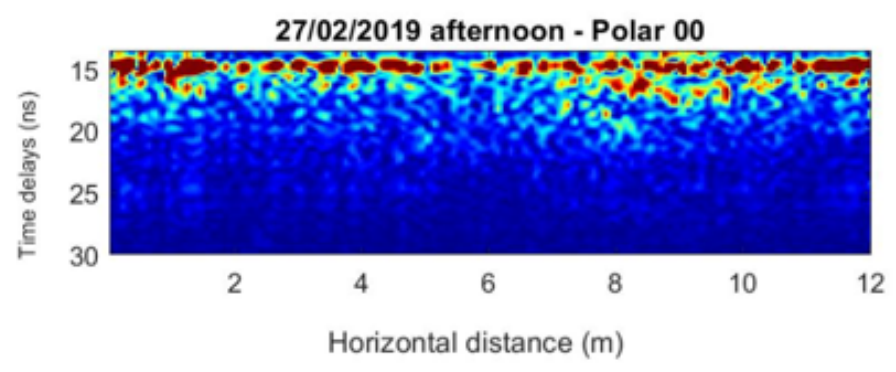

Figure 1-Radargram from the ATACAMA test campaign

The ExoFit test campaign conducted in the Atacama Desert in 2019 revealed a subsurface showing very little evidence of structures, and the radargrams acquired there are particularly interesting to test and validate the method developed initially on simulated data.

\section{Methods used}

\section{Simulation on TEMSI-FD}

In order to work in a totally controlled environment, the data used for the methods development have been simulated by FDTD (Finite Differences in Time Domain). All the models are generated using the Diamond-Square algorithm [1] which allows to generate fractal structures simulating natural heterogeneities of a given size and dielectric contrast. It is a fast and efficient method for generating a heterogeneous environment on a volume of several $\mathrm{m}^{3}$. This FDTD simulation software is TEMSI-FD, developed by a team from the XLIM lab of Limoges and the simulation parameters were set by the work of Yann Herve [2] in order to get a simulation considering the actual waveform of the signal and the radiation pattern of the WISDOM antennas.

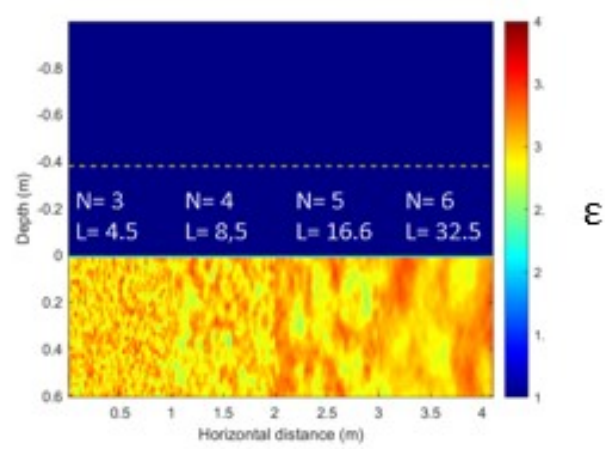

Figure 2 heterogenic environment simulated by TEMSI-FD

The two main variables parameters of the heterogeneous subsurface models are the size (L) of the heterogeneities and the mean dielectric constant $(\varepsilon)$ with maximum contrast.

\section{Bandwidth cutting}

WISDOM has a large bandwidth (from 0.5 to $3 \mathrm{GHz}$ ) which allows the detection of different reflectors, with a high resolution. The wavelengths are related to these frequencies with the equation: $\lambda=(c / \sqrt{ } \varepsilon) / f$ with $\lambda$ the wavelength, $c$ the speed of light in vacuum, $f$ the frequency and $\varepsilon$ the dielectric constant. The heterogeneities in the subsurface produce volume scattering, with an intensity directly correlated to the ratio between the wavelength and the heterogeneity size. The 
division of the bandwidth in 2 to 5 ranges will provide different results and their analysis will allow the identification of the wavelength for which the level of scattering is the highest, hence the characterization of the typical size of the heterogeneities.

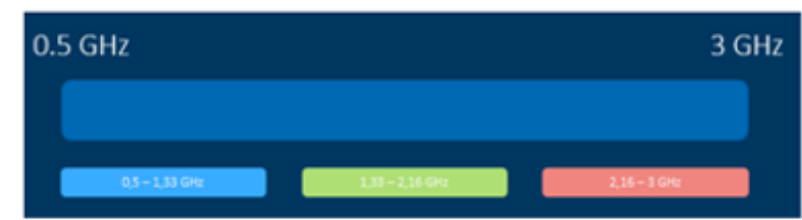

Figure 3 IIIustrotion of the whole frequency bandwidth split into 3 frequency sub-bands

\section{Sliding window and entropy}

Another approach to characterize through the diffraction induced is to locally measure the entropy on the radargram. A sliding window is used to scan the whole radargram. [3]. The entropy is given by $E(X)=\Sigma^{n_{i}} i=1 P_{i} \log 2 P_{i}$ where $P_{i}$ is the probability of amplitude level $i$ occurrence among $n$ (with $n=256$ for standard pictures) in the observed picture $(X)$. The entropy gives a representation of the "disorder level" in the observed area, and helps to detect the zones with the highest level of heterogeneity. The window's size will have an impact on the accuracy of the entropy detection and the resolution of the entropy picture obtained after the process. A good compromise will be selected depending on the size of the radargram and the targets.

\section{Preliminary Results}

The validation of the methods on simulated data before the automatization of the process and application to experimental WISDOM radargrams is an essential step. The bandwidth selection method has been applied to a simulation realised with TEMSI-FD, putting side by side zones of 1 -meter width with increasing heterogeneities like figure 2.

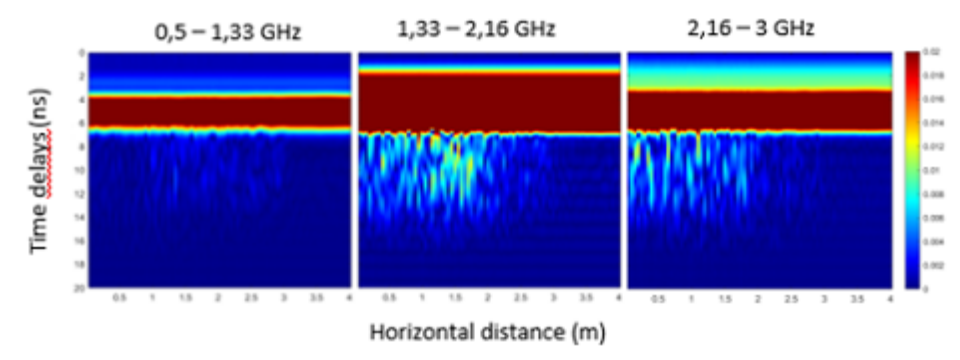

Figure 4 Results obtoined with the WISDOM bondwidth divided into 3 parts on simulated dato

The results show that the heterogeneities around $8 \mathrm{~cm}$ are especially diffracting for the middle bandwidth, which meets the expectations. A theoretical model will be implemented in order to find with precision the relation between the wavelength and the heterogeneity size. 


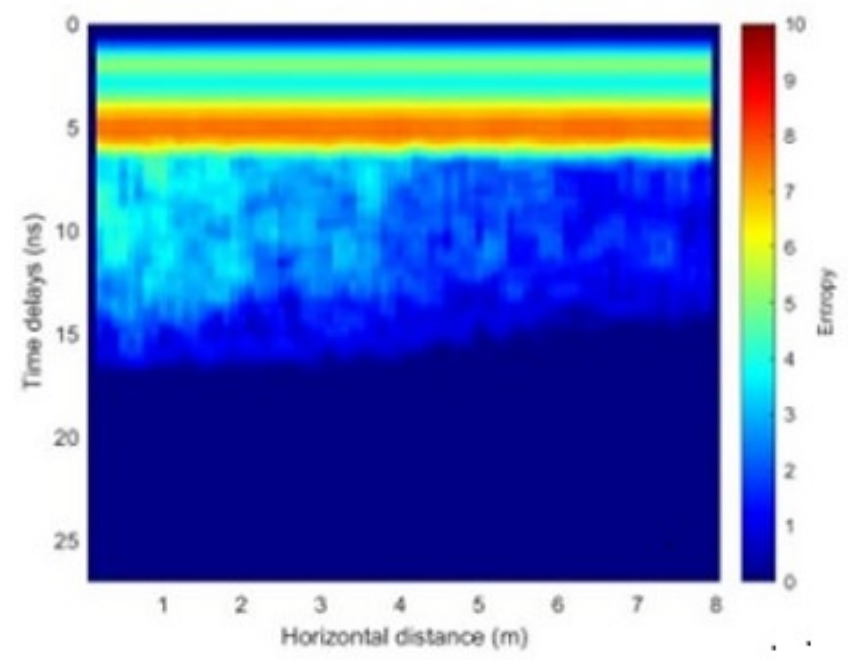

Figure 5 Entropy picture of a simulated radargrom

The entropy calculation within a sliding window shows a good detection of the different zones, and can also be used to detect the heterogeneities of dielectric constant. On the other side, as the echoes amplitudes are decreasing with depth in the radargram, this method is expected to be more efficient in the near subsurface.

The preliminary results obtained on simulated data are very promising. On-going work is done to obtain a quantitative characterization of the subsurface even in absence of a clear layering.

\section{References}

[1] Miller, G. (1986). ACM SIGGRAPH Computer Graphics, volume 20.

[2] Herve, Y. (2018). Le radar WISDOM a bord du Rover de la mission ExoMars : Caracterisation et preparation du retour scientifique.

[3] HARALICK M. et al. (1973) Textural Features for Image Classification.

Ciarletti V. et al. (2017), ASTROBIOLOGY Volume 17, Num 